\title{
Mapping smart experiences in tourism: A bibliometric approach
}

\author{
Mohammad Soliman', Lucília Cardoso ${ }^{2}$, \\ Giovana Goretti Feijó de Almeida 3 , \\ Arthur Filipe Araújo ${ }^{4}$ and Noelia Araújo Vila ${ }^{*}$
}

\footnotetext{
${ }^{1}$ University of Technology and Applied Sciences, Salalah College of Applied Sciences, Oman. Faculty of Tourism \& Hotels, Fayoum University, Egypt. Address: Salalah, Oman. Email: msoliman.sal@cas.edu.om

${ }^{2}$ CITUR, Leiria, Portugal. Address: Morges, Switzerland. Email: lucyalves.lucilia@gmail.com

3 CITUR, Leiria, Portugal. Email: goretti.giovana@gmail.com

4 Research Unit on Governance, Competitiveness and Public Policies, Aveiro, Portugal. Email: arthurfilipearaujo@gmail.com

5 Faculty of Business Sciences and Tourism, University of Vigo, Spain. Address: Ourense, Spain. Email: naraujo@uvigo.es

* Corresponding author
}

\begin{abstract}
There has been a significant increase in the number of studies addressing smart experiences in the context of tourism (SET). Nevertheless, no previous work has systematically and critically analysed the literature on this subject. To fulfil this gap, this paper examines the evolution of SET as a research topic by mapping the scientific production on it. To this end, 84 papers published from 2011 to April 2019 were retrieved from Scopus. To map this data, a blend of bibliometric analysis techniques, including the analysis of evaluative measures (productivity and impact metrics) and relational techniques (word frequency analysis and key theme analysis), was employed. Evaluative metrics were carried out using Plotly, Excel, and DB Gnosis software. The reviewed papers were then visually analysed through mind maps using BizAgi Process Modeler. The study presents an original theoretical insight, as well as a significant methodological contribution, as it employs an integrative approach of bibliometric analysis that relies on a set of rigorous techniques and can be implemented in future studies.
\end{abstract}

Keywords: Tourism; Smart experiences; Bibliometric approach; Evaluative metrics; Relational techniques; Mind mapping

Citation: Soliman, M., Cardoso, L., Almeida, G.G.F., Filipe Araújo, A. and Araújo Vila, N. (2021). Mapping smart experiences in tourism: A bibliometric approach. European Journal of Tourism Research 28, 2809. 


\section{Introduction}

Tourists' experiences are increasingly mediated and enhanced by information technologies, which, in turn, have significantly changed the way tourism is planned and managed. The search for information about destinations is now mostly done online (Walle, 1996; Xiang \& Gretzel, 2010). People's experiences within destinations are also increasingly connected either through real-time sharing or via utilitarian services. The set of all the interconnected systems and devices within a destination, including the whole tourism system, is referred to as a smart tourism ecosystem (Koo, Yoo, Lee, \& Zanker, 2016), that is, a system that combines the use of digital technologies and intelligent business networks as conceptual building blocks (Gretzel, Sigala, Xiang, \& Koo, 2015). All the elements of such an ecosystem must work harmoniously in order to provide tourists with smart experiences. According to Buhalis and Amaranggana (2015), in the context of tourism, smart experiences are provided by personalised services that are monitored in real-time and add value to tourists' experiences, while allowing sustainable practices.

The tourism industry deals with promising and facilitating experiences, as opposed to simple consumer goods or services. As recent studies show, an effective way to do that is involving tourists as active cocreators (Tregua, D'Auria, \& Costin, 2020) of their own experiences (Buonincontri \& Micera, 2016). Buonincontri and Marasco (2017) indicated how the use of technology improves the experiences of cultural heritage tourists. In this context, providing tourists with smart experiences is essential for destinations competing in the global market. Consequently, the subject of smart experiences in tourism (SET) is quite relevant for academics and practitioners.

As it is a particularly recent topic, very little is known about how to optimally provide SET. Destinations are still trying to adapt and figure out how to best employ the available technologies in order to achieve their marketing objectivities. Accordingly, academics are still trying to properly define terms such as smartness and smart experiences, finding the limits of their definitions and the overlaps with related topics (Gretzel, Zhong, \& Koo, 2016). Most importantly, scholars are still in search of the dimensions of SET, which may point to more effective ways to provide them (Buonincontri \& Micera, 2016; FemeniaSerra, Perles-Ribes, \& Ivars-Baidal, 2019; Gretzel, Ham, \& Koo, 2018). In this context, the present work aimed to answer the following questions: A) How has the study of SET evolved? B) What are the main subjects that have been studied within SET; and C) How have these topics been approached?

To tackle the addressed questions, this investigation employs an integrative approach encompassing bibliometric and key theme analysis. The use of bibliometric analysis on tourism literature is no novelty. Recent studies have employed this approach to grasp the current state and the main contributions in tourism literature as a whole (e.g. Güzeller \& ÇeliKer, 2018; Leong, Hew, Tan, Ooi, \& Lee, 202o), as well as in the tourism activity in specific locations (e.g. Meneguel, Rubio, \& Mundet, 2019) or in specific topics within the tourism industry, such as wine tourism (Sánchez, Del Río-Rama, \& García, 2017), adventure tourism (Cheng, Edwards, Darcy, \& Redfern, 2018), mountain tourism (Del Río-Rama, Maldonado-Erazo, Durán-Sánchez, \& Álvarez-García, 2019), tourism sustainability (Niñerola, SánchezRebull, \& Hernández-Lara, 2019), tourist tracking techniques (Padrón-Ávila \& Hernández-Martín, 2020), thermalism, thalassotherapy and spas (Del Río-Rama, Maldonado-Erazo, \& Álvarez-García, 2018), and smart tourism knowledge (Johnson \& Samakovlis, 2019). None of these studies, however, has systematically and critically analysed and mapped the scientific production on SET. More particularly, no study has employed a comprehensive approach of bibliometric analysis on big data research in SET. In addition, no known work has applied mind maps to analyse and visualise the key themes of SET. Therefore, within the present investigation, an integrative approach of bibliometric analysis was employed to map the academic literature on SET. More specifically, evaluative techniques were 
employed to measure the productivity and impact metrics of the SET-related data. Then, relational bibliometric techniques were applied to analyse word frequencies and key themes linked to this topic. In the end, a mind map was employed to visualise and broaden the understanding of the analysed theoretical categories.

The present study's findings present a relevant theoretical contribution on SET, as they provide a general idea of what most academic authors understand by it. This is an original outcome, as the literature on SET had not been critically reviewed or analysed in previous studies. Moreover, the study provides a methodological contribution, as it combines a set of bibliometric analysis metrics, which can be employed to map the state-of-the-art literature on other subjects in the future. Finally, the study's findings point to the need for future research on SET that indeed addresses tourists' experiences in the context of smart destinations. Such studies should generate useful insights for tourism product and destination managers aiming to capitalise on this trend by providing more meaningful tourist experiences. In the following section, we will demonstrate the literature review regarding the SET topic.

\section{Smart tourism and SET}

Over the last decade, new information technologies transformed every branch of economic activity, including the way people consume most products and services, as well as how they live various types of experiences. Therefore, they have naturally also transformed the tourism industry (Porter \& Heppelmann, 2014). The fact that information technology (IT) has developed alongside tourism since the 1970s paved the way for a revolution in tourism products and services (Koo et al., 2016), and consequently, in the structure of the tourism industry (Sigala, 2015). In parallel, the recent shift in tourists' lifestyles has significantly transformed the current scenario of tourism investigation (Hwang, Park, \& Hunter, 2015), leading to new research methods, such as analysis of social media, blogs and specialised websites. Such developments have also led to a whole myriad of new tourism-related phenomena and concepts, including smart tourism and SET.

Smart tourism and SET are the next logical and evolutionary step from e-tourism. The concept of etourism arises from the application of information technologies to the commercialisation of tourism products, focusing on the computerisation and virtualisation of tourist exchanges and the exploration of value chains. In this context, e-tourism encompasses all phases of tourism consumption (pre-trip, during trip and post-trip) (Gretzel, 2018). For instance, tourists search for information and make reservations prior to the trip; use navigation services and share their experiences in real-time during the trip; and keep sharing and engaging with friends through content related to the trip afterwards. Academic research on this topic focuses on the study of e-destinations (Buhalis, 2003), especially on how they are influenced by information and communication technologies.

The scenario where tourism management and consumption are significantly enhanced by information technologies is referred to as smart tourism, which is conceptualised in several different models. Gretzel et al.'s (2015) "Components and Layers of Smart Tourism Model”, for instance, works on a pillar system, where the "smart tourism" concept is the top layer and the "smart destination" is the bottom layer. The intermediate level includes "smart businesses" and "smart experiences". Finally, mega data (including data collection, sharing, and processing) along with conventional, intelligent tourist management systems, connect all the pillars.

Another important conceptualisation is provided by Gretzel et al. (2018), who describe smart tourism as containing five layers: (1) a physical layer, which includes natural and man-made tourism resources; (2) the layer of intelligent technologies, which relies on physical infrastructures to provide back-end 
business solutions and front-end consumer applications; (3) a mega-data layer, which includes data storage, open data clearinghouses and data-mining applications; (4) a business layer, which employs the available technology and data to innovate and achieve competitive advantages; and (5) an experience layer, where data-enhanced experiences result from the use of new technologies. Considering these conceptualisations, smart tourism can be defined as a smart way to diagnose, plan, and manage tourism using information technology.

Finally, Femenia-Serra and Neuhofer's (2018) four dimensions of smart tourism experiences also deserve special attention. According to this conceptualisation, SET must be: i) data-driven, ii) built in real time, iii) based on context-awareness, and iv) co-created. Being data-driven means that SET must be provided by using big data as a source of intelligence for decision making, for example, in destination planning and marketing. Being built in real time refers to the dynamic interconnection allowed by the ICTs, which allow service providers to obtain real-time knowledge about tourists' needs and desires. Being based on context-awareness means that experience providers need contextual information on both the tourists (e.g. personality and values) and the destination (e.g. climate) in order to provide relevant offers. Finally, being co-created means that SET deliver real value to all stakeholders within the destination by involving them in the decision-making process and allowing tourists to play an active role in the creation of their own experiences.

When dealing with technology-related phenomena, such as smart tourism, it is important to bear in mind that technology is always further developing. As part of this constant evolution, technology is increasingly present in tourists' experiences. Accordingly, the systems and devices that enhance such experiences are increasingly interconnected. The set of interconnected systems and devices within a destination integrate the smart tourism ecosystem (Koo et al., 2016), which must be harnessed by destinations willing to enhance tourists' experiences using ICTs, that is, to SET. In this context, destinations that manage to achieve competitive advantages by using smart technologies are referred to as "smart destinations".

Tourism deals with marketing experiences and providing the necessary services and conditions for people to live them in the best way possible. As observed by Pine and Gilmore (1998), experiences are as different from services as services are from consumer goods, which brings additional challenges to the marketing and managing of tourism products. Smart technologies might facilitate this process, helping destinations and service providers create the necessary conditions for their consumers to have more meaningful, fun, and engaging experiences. However, to achieve this, they need a comprehensive understanding of how to employ the available technologies to create an effective and harmonious smart tourism ecosystem. Given this scenario, gaining knowledge and insights on SET is essential for tourism academics and practitioners. Nevertheless, the state of the art on SET is far from providing all the answers for tourism product and destination managers aiming to achieve competitive advantages using smart technologies. In fact, as a very recent research topic, it still presents significant knowledge gaps, which currently limit its usefulness in the industry.

Amongst the research gaps on SET, Femenia-Serra et al. (2019) and Gretzel et al. (2018) call for studies on tourists' perceptions about their experiences in smart destinations. Additionally, Femenia-Serra et al. (2019) point out the lack of conceptual schemes that characterise tourists in the context of smart destinations. Finally, Gretzel (2018) argues that smart tourism destinations must actively work towards providing tourists with positive experiences. However, there is not yet a comprehensive understanding of the best practices to make effective use of smart technologies in order to provide satisfactory tourist experiences. The present work aims to contribute to the clarification of how destination managers can 
use information technologies to provide tourists with richer experiences by mapping the state of the art on SET. The methodological steps carried out to achieve this goal are outlined in the next section.

\section{Methodology \\ Data Collection}

The data collection procedures took place in April 2019 and consisted of a search for journal articles addressing SET, written in English, and published on Scopus' database from 2011 to April 2019. Scopus' Database was chosen as a data source because it is one of the largest top-quality abstract and citation datasets of peer-reviewed literature on the web (Bosman, Mourik, Rasch, Sieverts, \& Vrehoeff, 2006). The publication period was chosen as an outset point for the growth in the number of SET studies. To filter studies on SET, the search was limited to articles containing "smart experiences + tourism" within their title, abstract and keywords. Eighty-five papers were gathered, from which, one was considered not relevant to the context of tourism, and consequently excluded, after an initial screening. Therefore, the final database consisted of 84 articles.

\section{Analysis Techniques and Procedures}

The current paper employed a thorough bibliometric analysis, including two main techniques, namely evaluative methods and relational methods. Within the evaluative techniques, three types of measures/metrics were analysed: (1) productivity measures; (2) impact metrics; and (3) hybrid metrics (Benckendorff \& Zehrer, 2013; Koseoglu, Rahimi, Okumus, \& Liu, 2016). In this context, productivity and impact metrics were used to rate the main trends and evolution of SET-related research, as done in previous tourism studies (e.g. Fahimnia, Sarkis, \& Davarzani, 2015; Koseoglu et al., 2016; Del Río-Rama et al., 2018; Del Río-Rama et al., 2019; Ye, Song, \& Li, 2012; Padrón-Ávila \& Hernández-Martín, 2020). To this end, the retrieved articles' bibliographic information was organized, classified, and summarised in an excel spreadsheet. The data were then analysed through evaluative metrics, which were carried out with the help of a set of software packages. More specifically, analysis procedures, such as the examination of papers by publication year, journal productivity, subject categories, citation analyses, and geographical location of research institutions, were performed using both Microsoft Excel and Plotly. Meanwhile, the analysis of papers by subject areas, author influence and affiliation influence were performed on DB Gnosis software (see DB Gnosis http://favouritedestinations.com/en/dbgnosis/).

Concerning relational bibliometric methods, this study applied word frequency analysis and key theme analysis to explore contents and relations amongst the research topic and its associated themes and methods. First, word frequency analysis, a method of content analysis, was used to quantify qualitative data (Schreier, 2012). Within tourism studies, this technique is used not only for bibliographic analyses but also for purposes such as examining tourists' destination imagery processing (e.g. Cardoso, Dias, de Araújo, \& Marques, 2019). Within the present investigation, the technique was operationalised mainly through frequency counts on DB Gnosis. The first frequency count was applied to keywords. In this instance, the data were simply loaded into DB Gnosis and subjected to the "Count + Rank" function. The procedure applied in the frequency count for titles, abstracts and keywords was slightly more complex, as there was more text data to deal with. In this context, the first step after loading the data into DB Gnosis was removing "stopwords", that is, terms that are deliberately excluded from a list of words before analysis because they do not have any semantic value and would only generate noise in the result. In word counts, it is common to exclude operational words, such as articles, pronouns, conjunctions, prepositions, adjectives, and adverbs (Molinos, Mesquita, \& Hoff, 2016). With the operational words removed, a "Query + Ranking" function was applied in order to rank the remaining words. Then, regarding key themes analysis, papers were described according to the following six 
variables: study focus, key topics, theoretical contributions, research method, applications to tourism, and suggestions for future research.

Subsequently, results were summarised in a mind map, a visual resource proposed by Buzan (2013) in the 1970s, which consists of a graphic thought ordering process that creates connections between the content displayed and is most commonly used for education purposes. It should be noted that there is still little scientific research that uses this visual tool. In this regard, Wheeldon (2011) and Almeida (2018) used mind maps to visually outline and analyse concepts and generate associations between them. Although it may seem that it is just a visual organization tool, mind maps assist in interpreting and linking ideas in various quantitative and qualitative analysis procedures. This results in more in-depth insights generated through a greater volume of textual or numerical data. Within the present study, mind maps were made using XMind (to design the research) and BizAgi Process Modeler (for data analysis). XMind is a popular mind mapping and brainstorming software, which captures ideas and manages complex information, as well as promotes team collaboration. Within the present study, it was employed to help understand the complexity of the analysed subject. BizAgi, in turn, is a Business Process Model and Notation (BPMN) tool that creates mind maps, flowcharts and diagrams in general to facilitate the graphic and logical organisation of relationships between subjects. Within the present study, BizAgi was employed to classify the analysed studies through different criteria, namely: a) year, individually and through 3 year-periods (2011-2013, 2014-2016 and 2017-2019), and, b) categories, both individually and gathered in sets. The software was also employed to make two types of mapping: horizontal and vertical, which facilitate the visualisation of the correlations between categories.

\section{Results}

Productivity and impact metrics

The analysed data reveal the trend in the number of articles addressing SET published from 2011 to April 2019. Overall, it is evident that research on SET is still experiencing a growth in popularity, as the yearly number of papers increased from only one in 2011 to 10 papers in 2015, and then reached a peak of 25 in 2018. The apparently low number of papers published in 2019 is explained by the period of the research, which ends on the $17^{\text {th }}$ of April 2019. In this context, these nine papers reflect the production of the first quarter, which corroborates the upwards trend. In terms of journal productivity, as shown in Figure 1, Sustainability clearly has the highest number of publications (11) on SET, followed by Journal of Destination Marketing \& Management (5) and Tourism Review (4). Two other journals - Technological Forecasting \& Social Change and Asia Pacific Journal of Tourism Research - have three publications each, while six journals published two articles. All the other journals had only one publication on the subject.

Regarding the subject category of journals on which most papers were published, 'Geography, Planning and Development' leads the rank with 28 papers, followed by 'Business and International Management' (8 papers). The remaining categories account for 2 to 4 papers each. The results on publications on SET by subject category are summarised in Figure 2. 


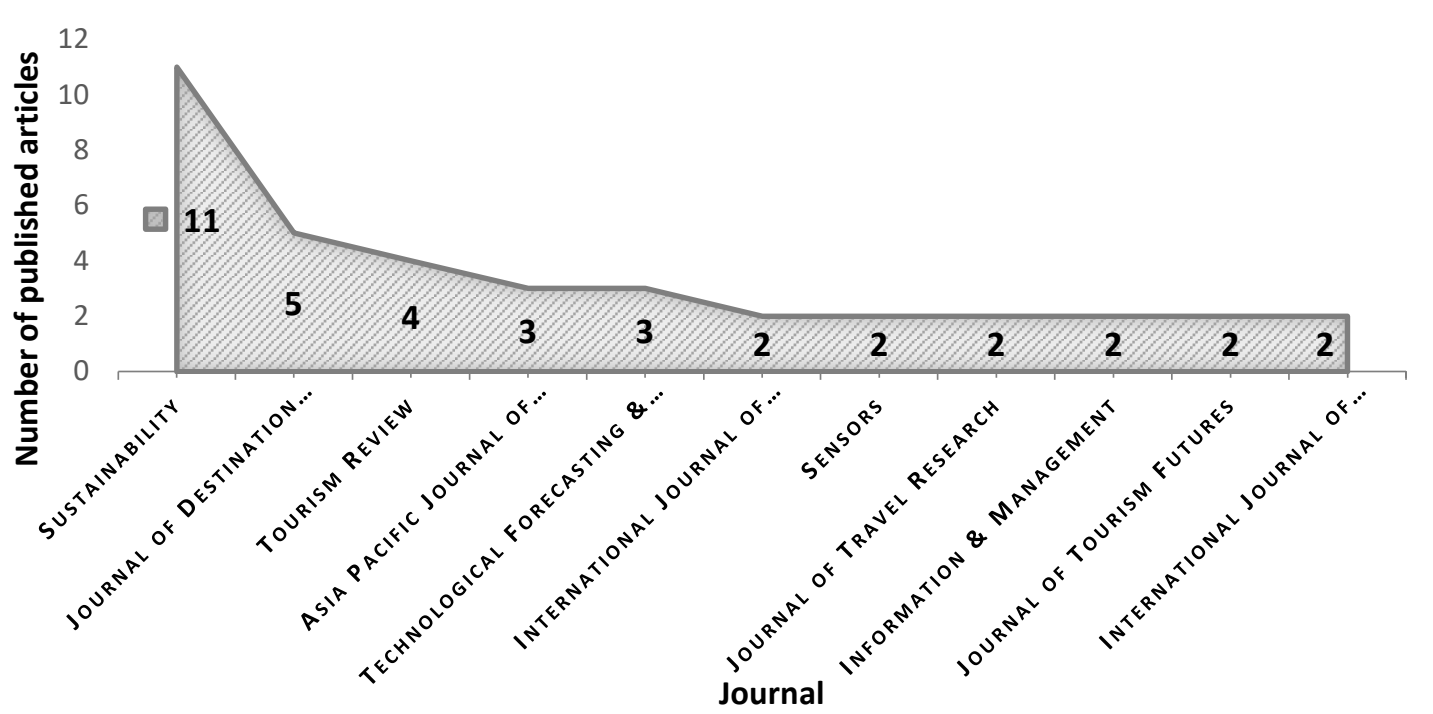

Figure 1. The most publishing journals contributing to the area of SET

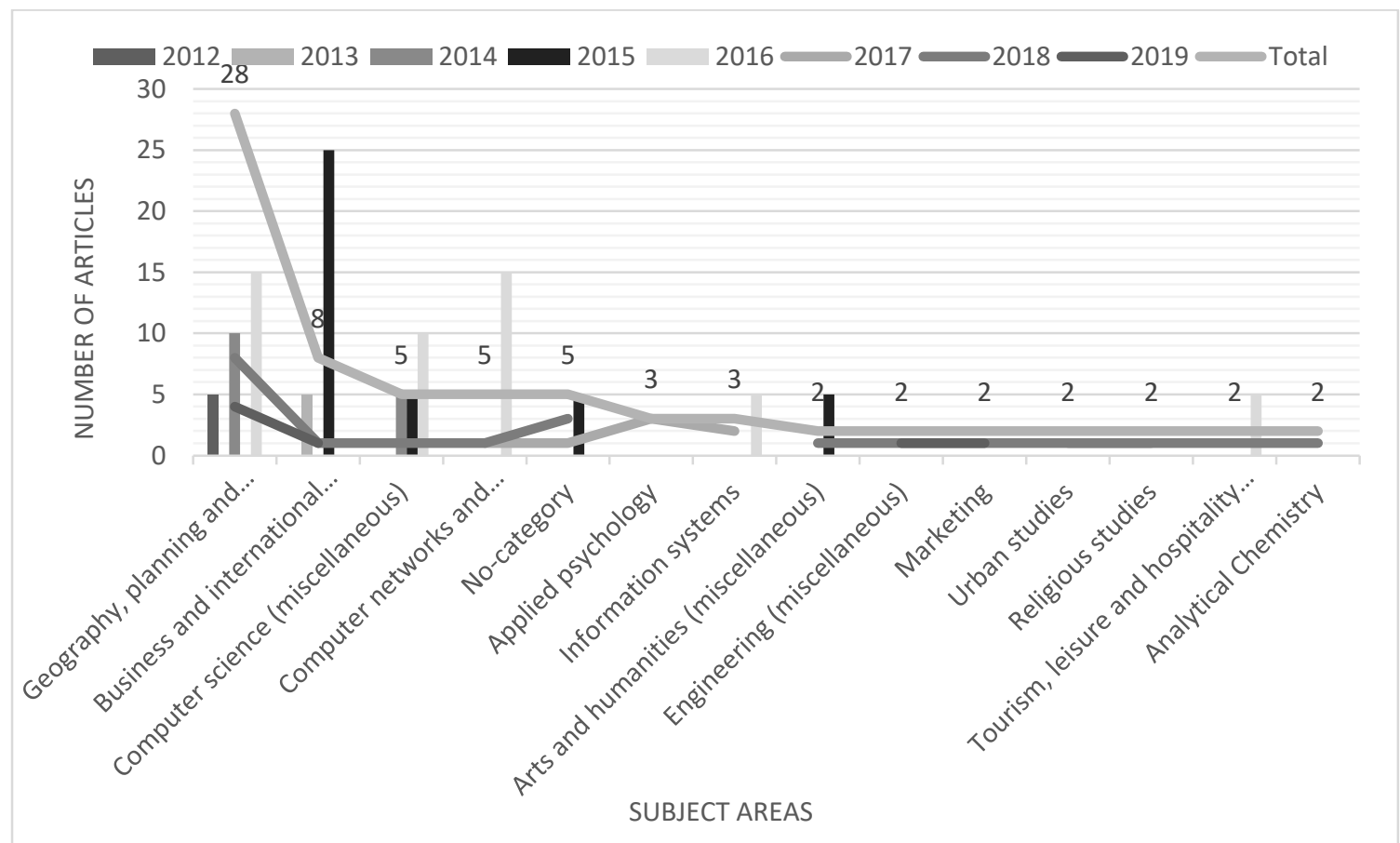

Figure 2. Top subject categories of journals ordered by published articles on SET

Regarding articles' top ranking on SJR-2018, as shown in Figure 3, papers no. 18 and no. 83 (see Appendix 1), both published on Journal of Travel Research, are the ones with the highest rankings (3.18). These papers have 23 and 254 citations, respectively. The lowest values are presented by paper no. 45, published in Current Issues in Tourism (1.42 - no citation). Another key point is that all journals are Q1journals (top quartile) on the SJR ranking. 


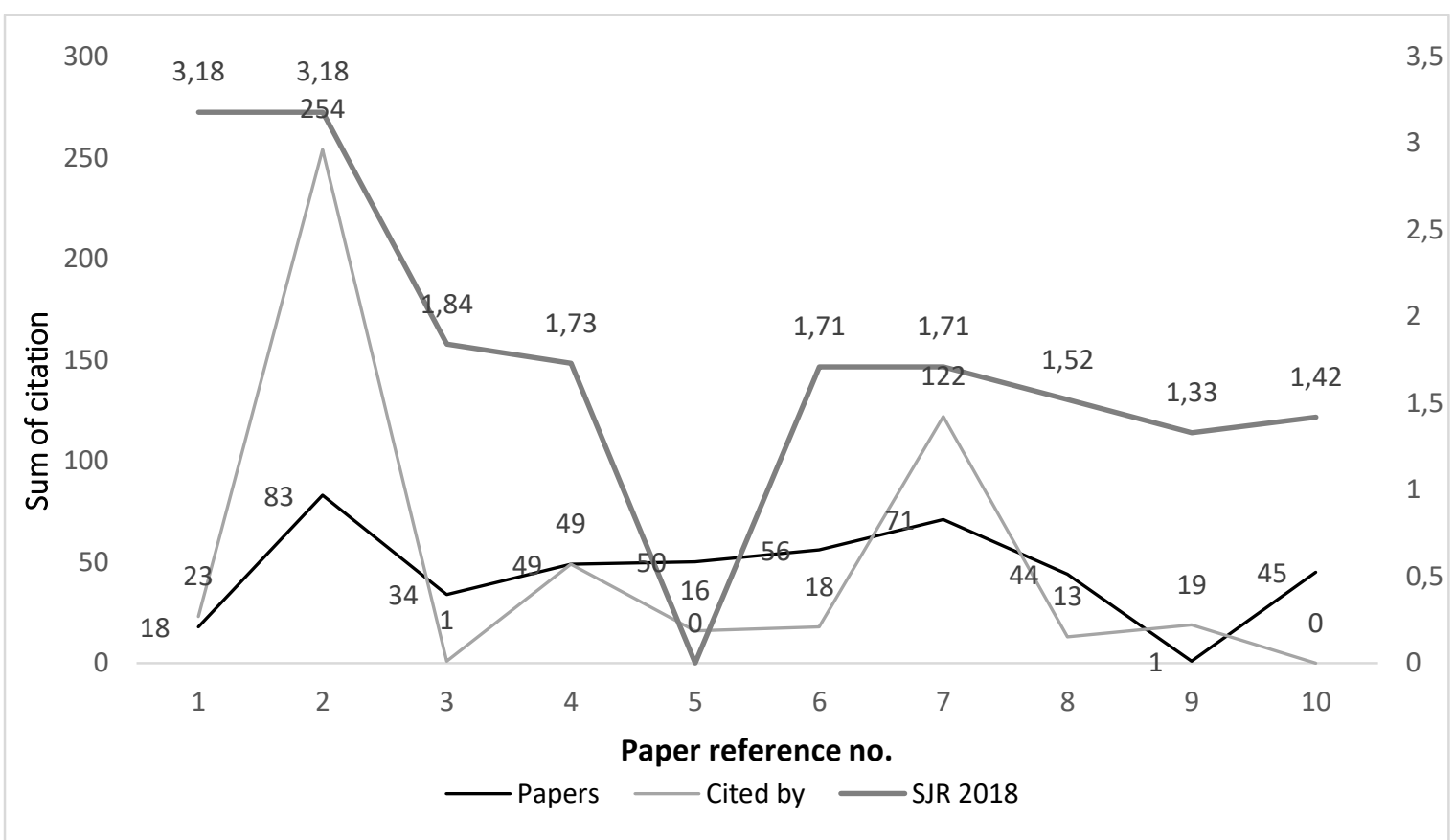

Figure 3. Top 10 ranked articles on SET by SJR 2018

Concerning journals' influence, Journal of Travel Research is by far the most influent on the topic of SET, with 277 citations during the reference period. The second most influent is Journal of Destination Marketing $\mathcal{E}$ Management, whose papers on SET were cited by 209 other studies during the period. The three following journals are Computers in Human Behavior, Electronic Markets and Information $\mathcal{E}$ Management (122, 95 and 65 citations, respectively). Although Sustainability has the highest number of published articles in the subject of SET (11), as shown in Figure 4, these papers only got 58 citations. Moreover, Journal of Sustainable Tourism had 46 citations, while Information Technology E Tourism had 38. Finally, both EPJ Data Science and Information Processing and Management had 37 citations.

Papers were also analysed in terms of the geographical locations of the research institutions to which their authors are associated. To this end, an excel spreadsheet containing one column for each country was created. Figure 5 shows the top countries in terms of the number of published articles on SET. It is notable that South Korea has the best record in terms of publications, with 26 articles. This result is in line with the figures presented in Table 2, in which the three most prolific authors are affiliated to Kyung Hee University, South Korea. The second most prolific country is Italy, which has contributed with 13 articles during the analysed period. Next, the USA, UK, and Spain have published 12 papers each. With a significantly smaller production, Taiwan, Brazil, and Croatia have published five papers each, while UAE, Greece, Portugal, and China published four each.

The last categorical variable through which papers were classified was the area of knowledge covered by the journals in which they have been published. As shown in Figure 6, "Social sciences" leads the rank with $28 \%$ ( 42 articles) of the papers, followed by "Business, management and accounting" and "Computer sciences", which account for 21\% (35 articles) each. Other relevant areas of study are "Environmental sciences", with 15 papers, and "Energy", with ten. Several other areas have contributed 
with fewer than ten papers each. It should also be noticed that some journals are categorised in more than one area, which explains the fact that the sum of percentages exceeds $100 \%$.

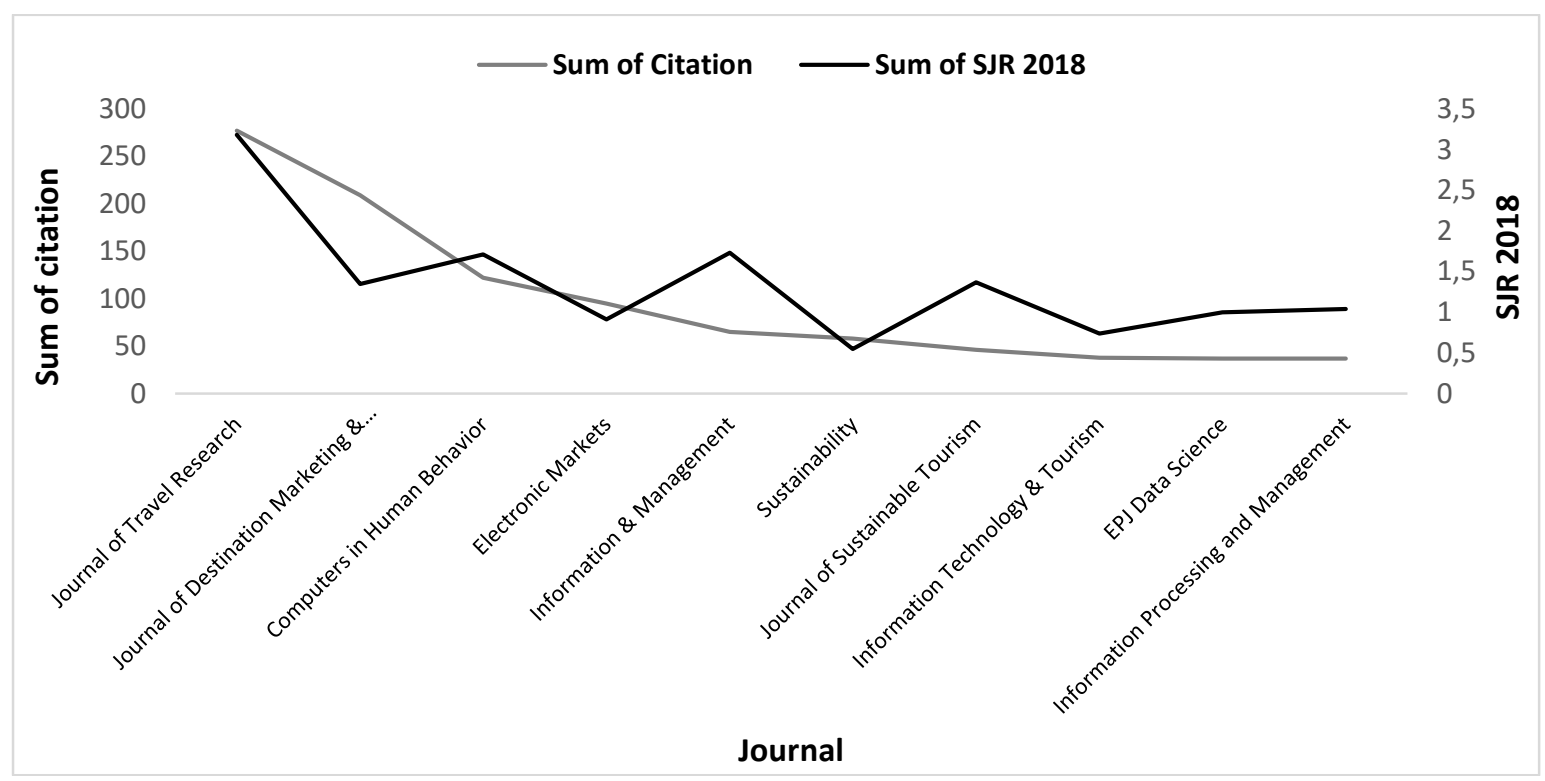

Figure 4. Top 10 most-cited journals in SET and their SJR rank in 2018

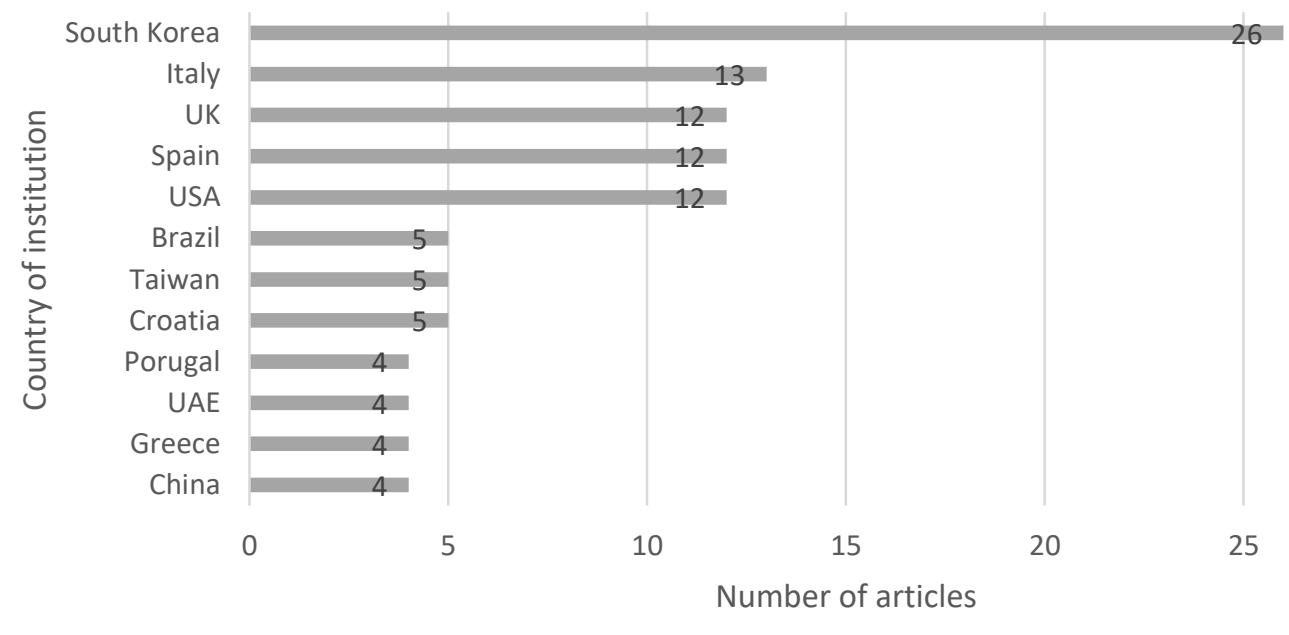

Figure 5. The most prolific countries in the field of SET 


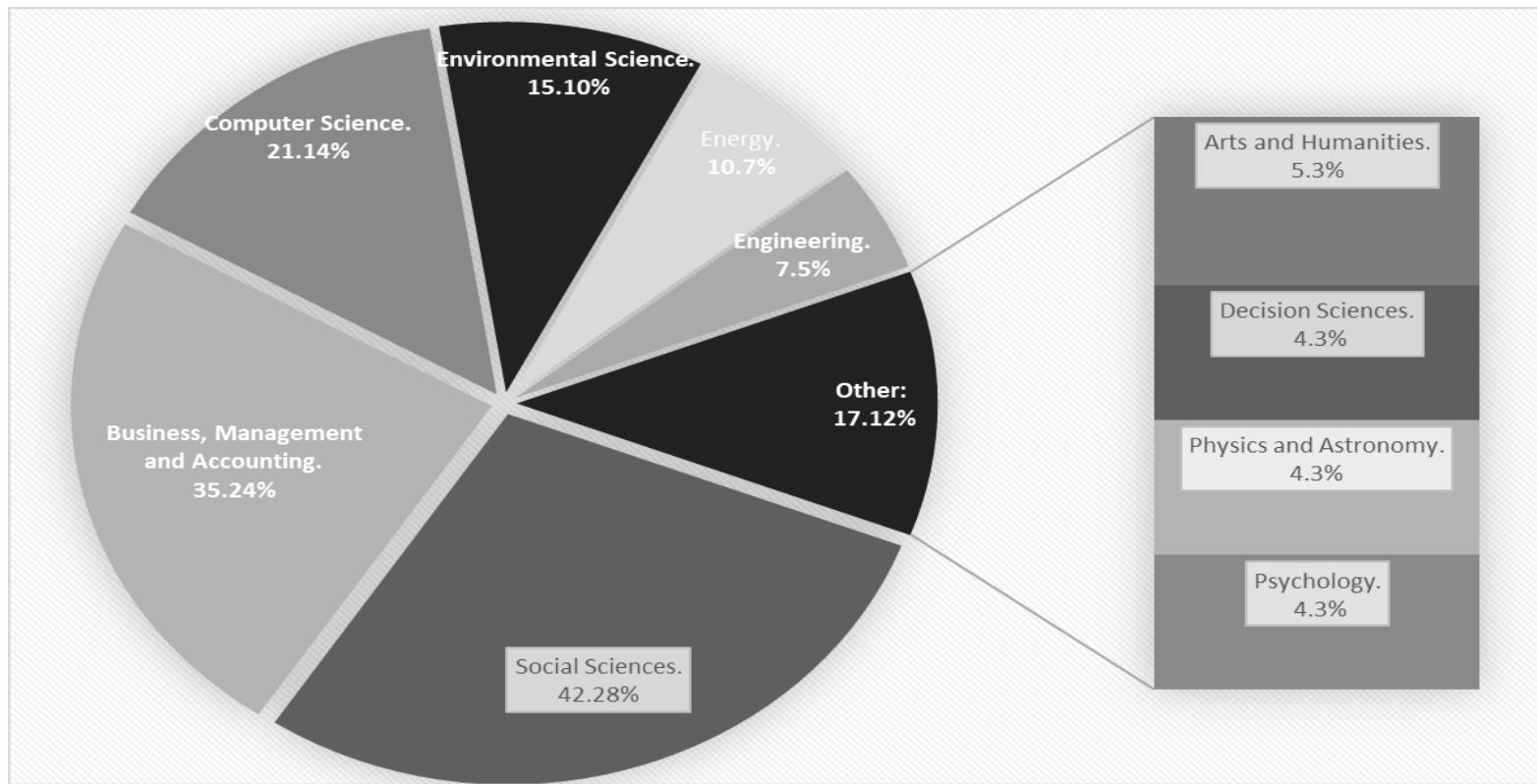

Figure 6. The top 10 journal subject areas of published papers on SET

Finally, the retrieved literature was analysed in terms of the most prolific authors. In this vein, not only the number of papers published by each author was considered, but also the number of citations each paper and author got, as it is a more precise indicator of the authors' and papers' impact factor.

As shown in Table 1, these two variables are not always directly proportional. For instance, Chung, N. is the author who published the most papers on SET. However, authors like Koo, D., Buhalis, D. and Park, S. were cited significantly more, even with a considerably lower number of papers. In the most expressive case, Park, S.'s two papers were cited in 257 other documents, against only 53 of all seven papers published by Chung, N. In other words, the former has an average of 128.5 citations per paper during the reference period, while the latter has only 7.6. Therefore, although Chung, N. is the author with the most publications, he/she is far from being the most influential. This position is achieved by Park, S., followed by Koo, D. and Buhalis, D.

\section{Word frequency analysis}

Word frequency was initially analysed through keyword counts, which were carried out on all the 84 papers, resulting in a total of 474 words, with an average of 5.64 keywords per document. The initial word sample from the 84 titles included 987 words. From those, 253 were excluded, resulting in a final sample of 734 words. The initial sample from abstracts included 15840 words, from which 5100 were excluded, resulting in a final sample of 10730 words for analysis. Table 2 summarizes the top 20 most frequent words on titles, abstracts and keywords. As expected, "smart" and "tourism" lead the rank, with $5 \%$ each, followed by "experience", with a $1 \%$ relative frequency.

Key theme analysis

A mind-map was employed to analyse key theme variables, including four main steps, as shown in Figure 7. For analysis purposes, the mind maps were grouped by three-year periods: 2011-2013, 2014-2016 and 2017-2019. 


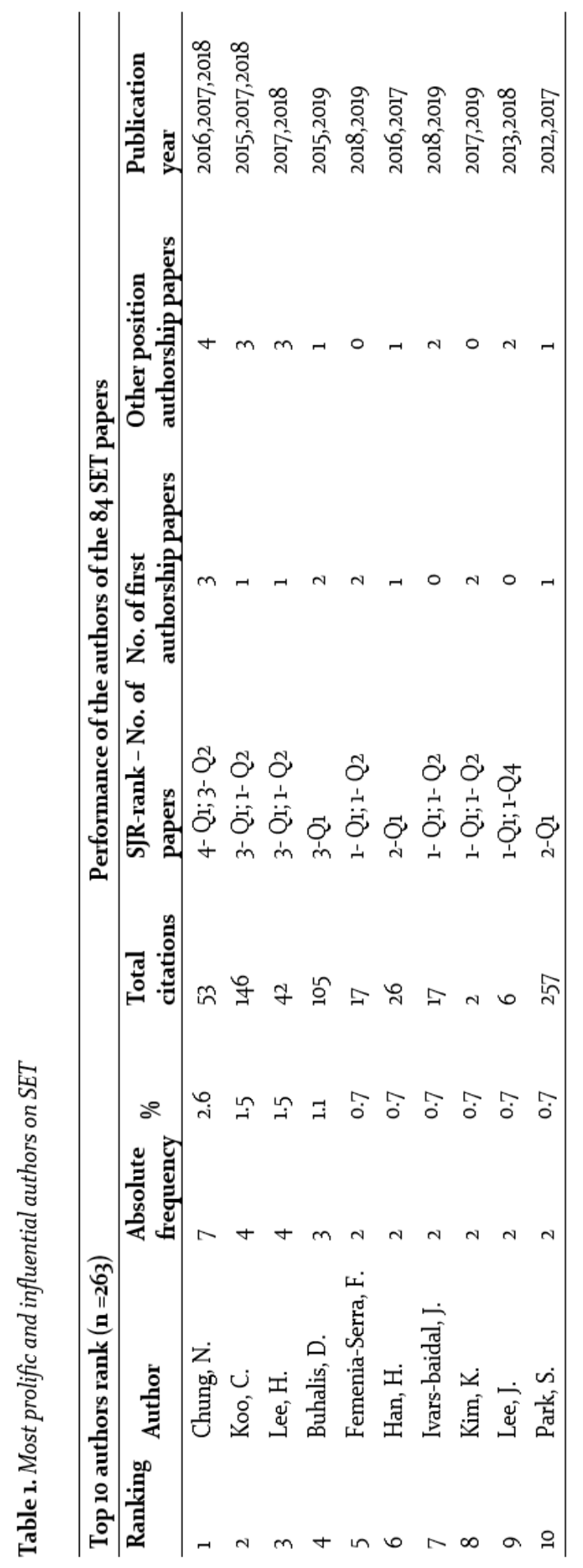


Mapping smart experiences in tourism: A bibliometric approach

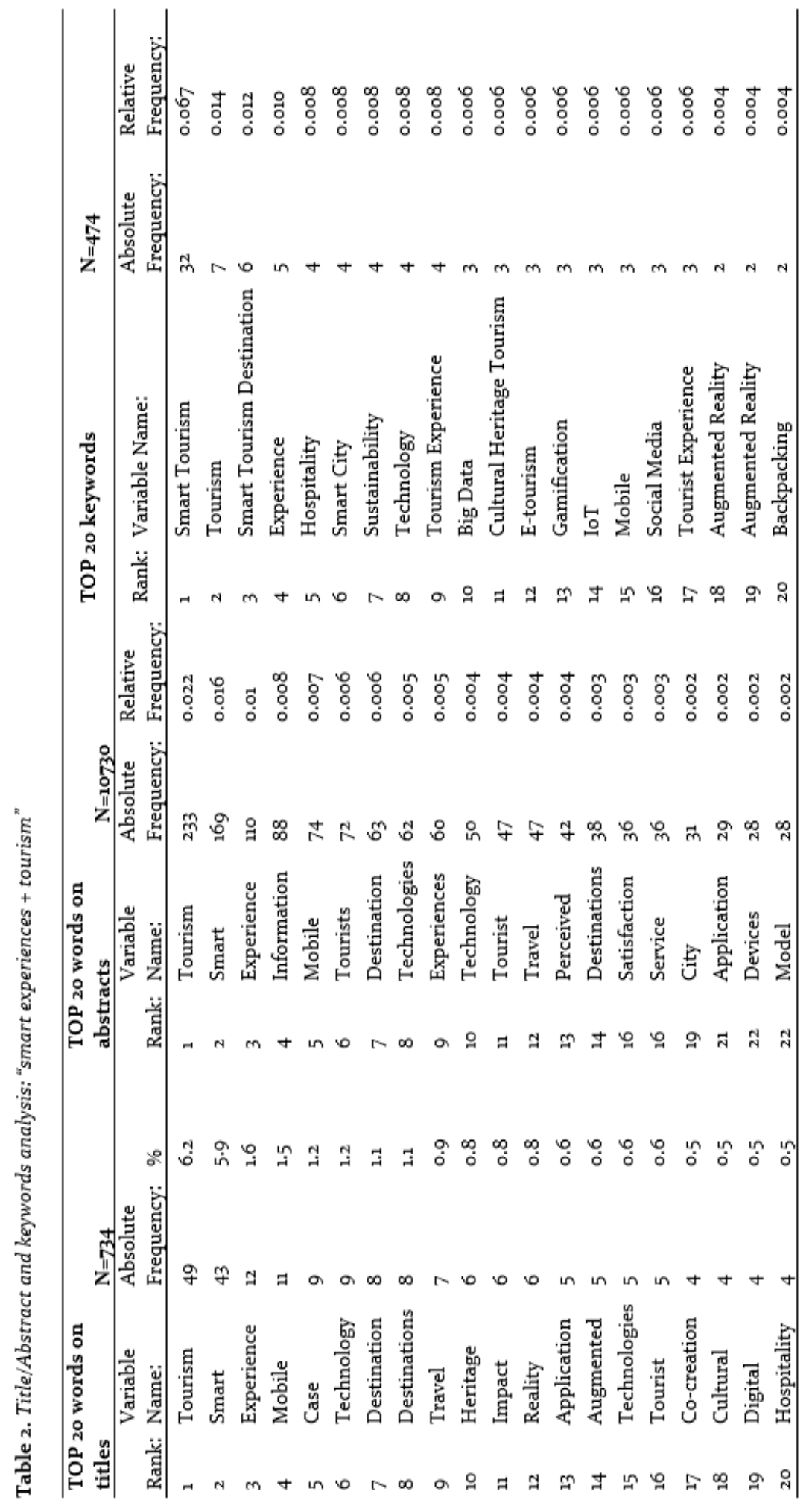




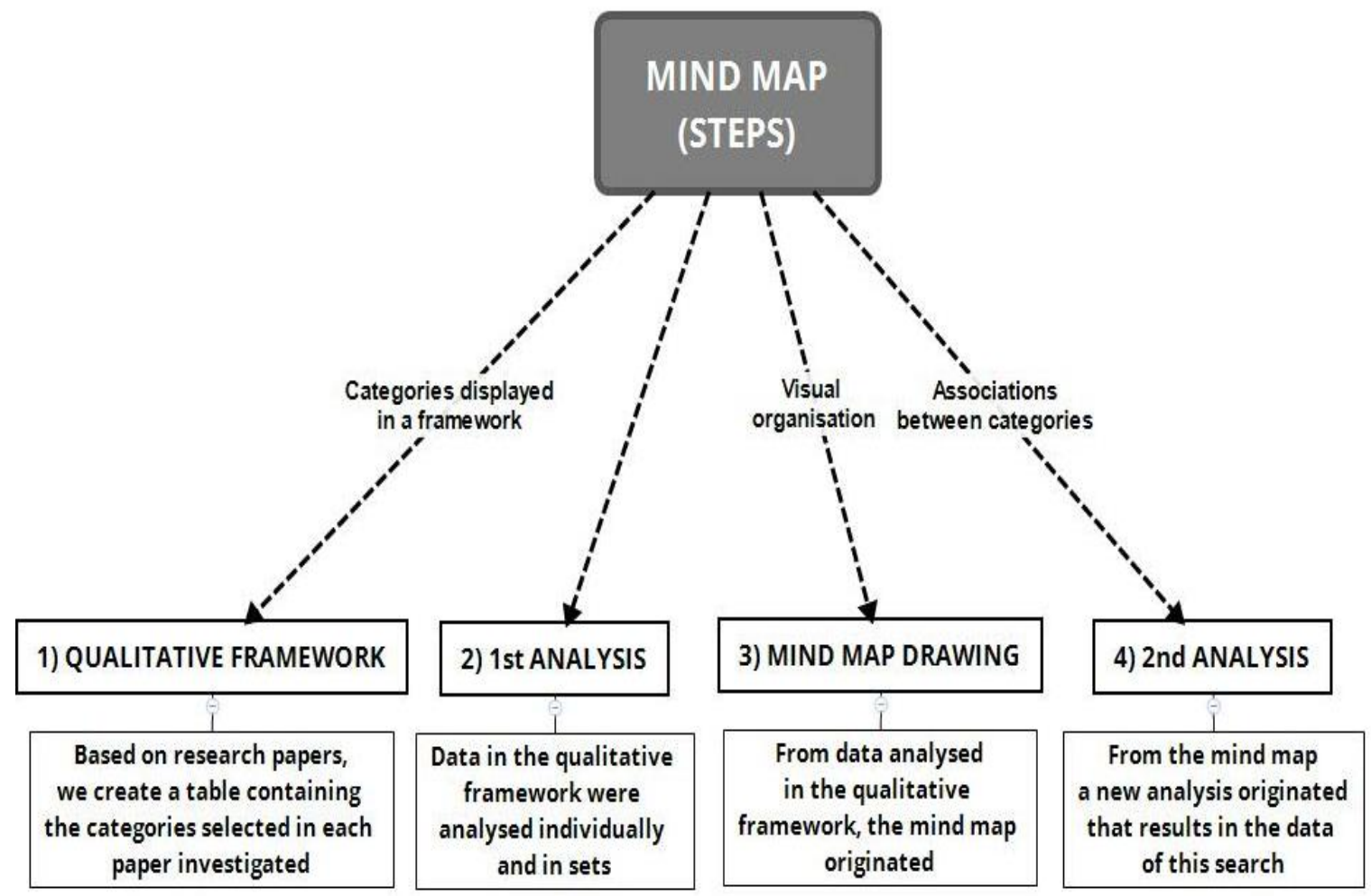

Figure 7. Steps of mind map analysis

In 2011, the key theme was a scanned mapping application. In 2012, the focus remained on applied technology, as studies mostly addressed the use of smartphones. In the following year (2013), the concepts "e-tourism", "mobile applications", "visitor experiences" and "local environment" also emerged as relevant subjects. Key themes from 2011 to 2013 are summarised in Figure 8. As shown in Figure 9, "augmented reality" emerged in 2014, and a series of themes, such as "technological sensors" and "smart technologies" emerged in 2015, a particularly fertile year for this research field. Within this short period of time (2014-2015), a special interest in studies on the application of new technologies in the tourism industry was noticed. Some of those studies went as far as including tourism into discussions on "smart cities". The mind map also reveals that, up to 2015, the focus starts to change, as "smart experiences" emerges as a popular topic. Also in 2015, studies addressed technological potential and voluntary tourism. Even so, the focus of studies remained on the technologies per se, as opposed to tourists' experiences. In the following year, 2016, key topics considerably broadened. Papers from this year focus on "innovation", “management", "mobile tourism”, "smart glasses", “technologies”, "smart devices", "augmented reality”, “smart tourism”, “tourists' experiences”, “cultural heritage” and "geographical determination". However, the focus is still on the technology, particularly on augmented reality. In sum, up to 2016, "smart experience" does not appear as a key theme, although the term "smartness", understood as the smart use of technology, is frequently employed in many studies. 


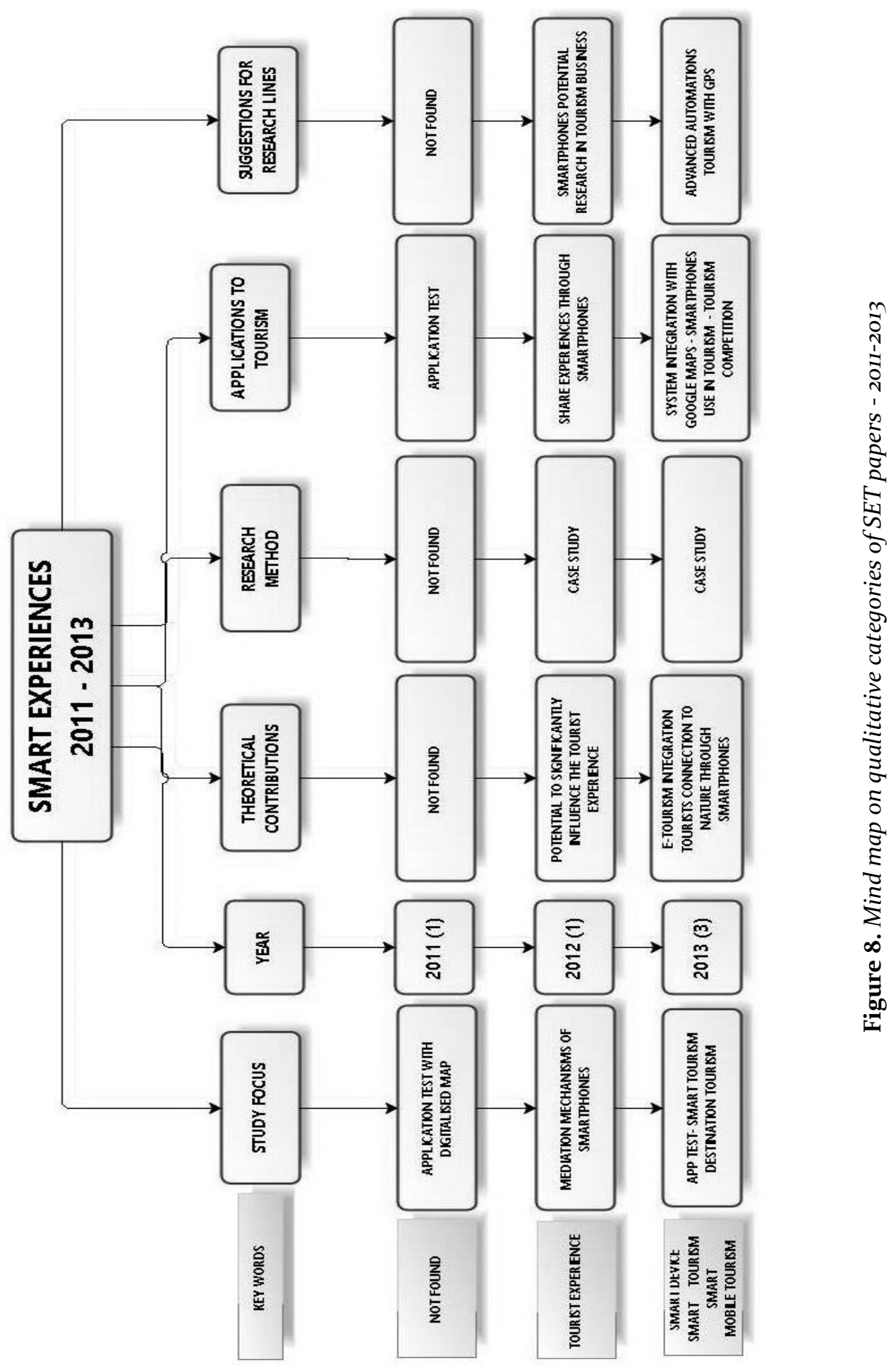




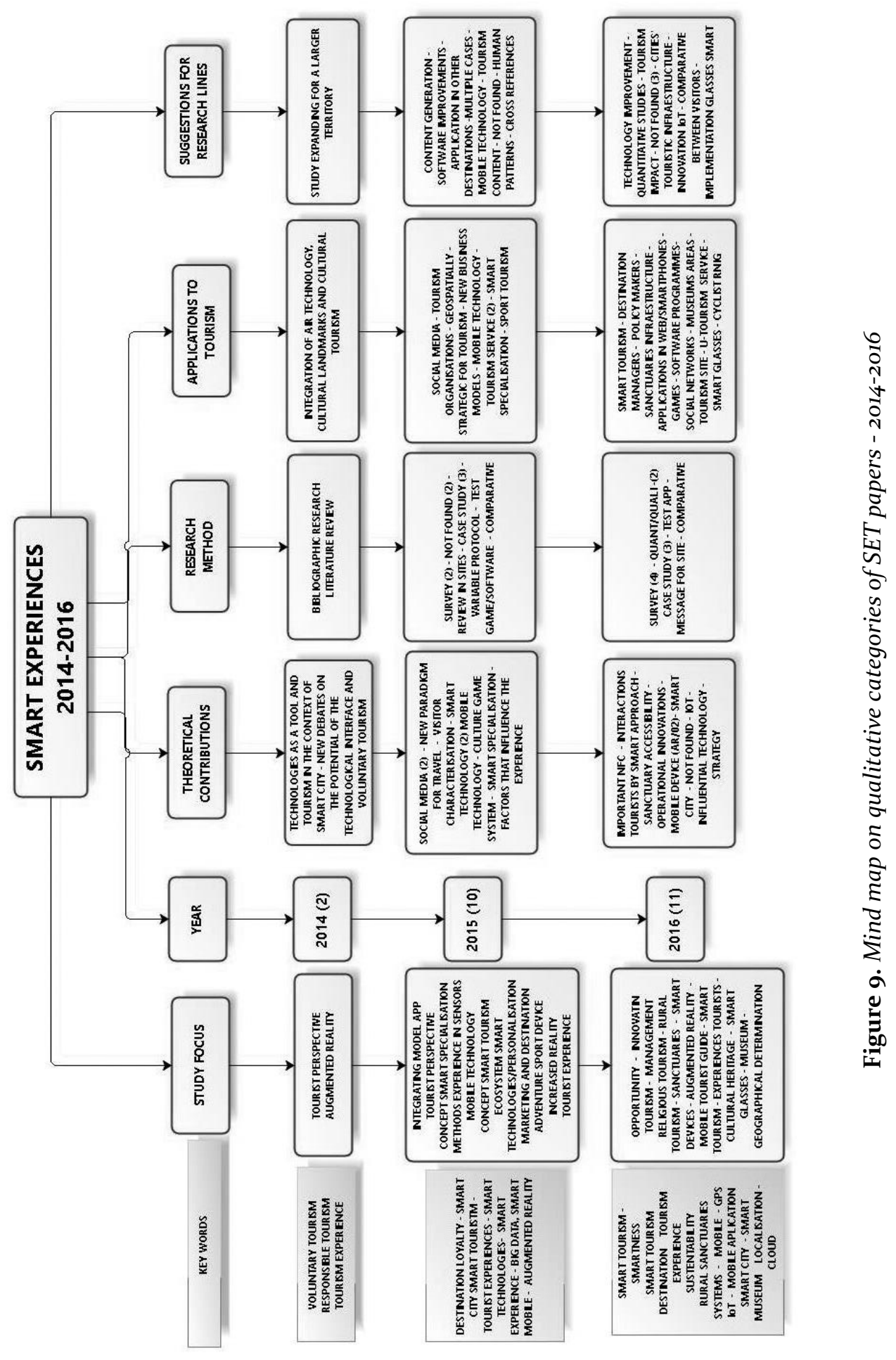




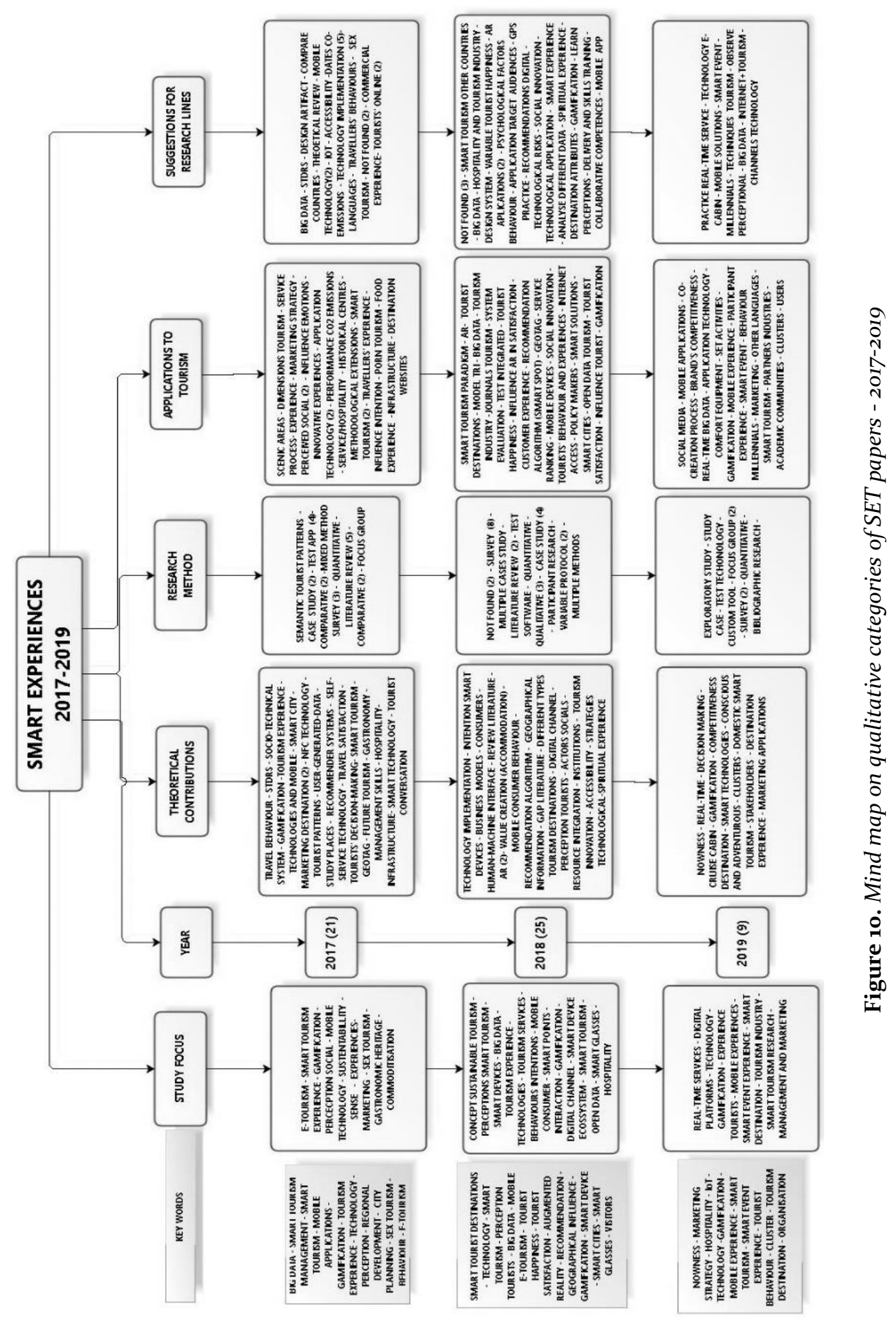




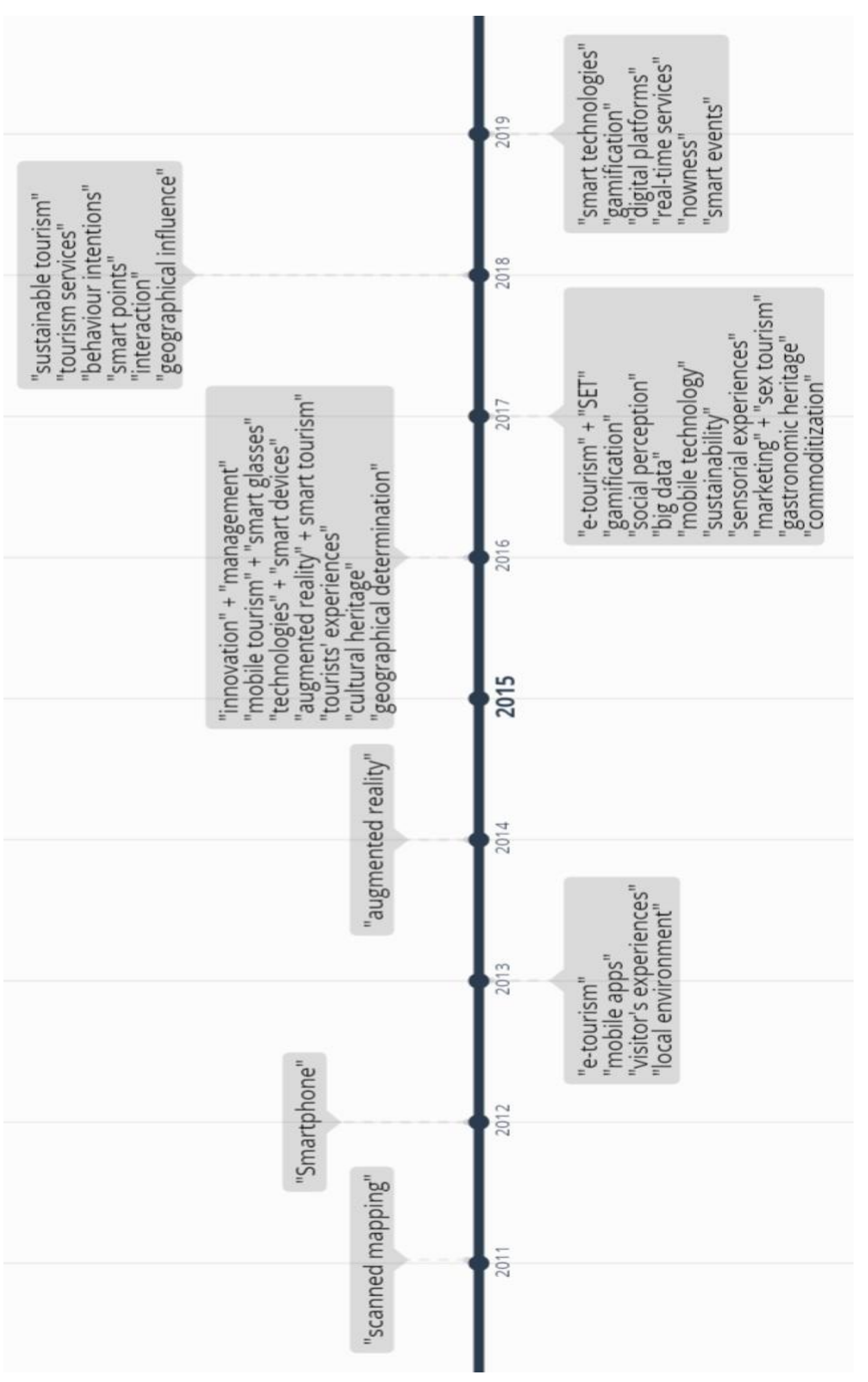




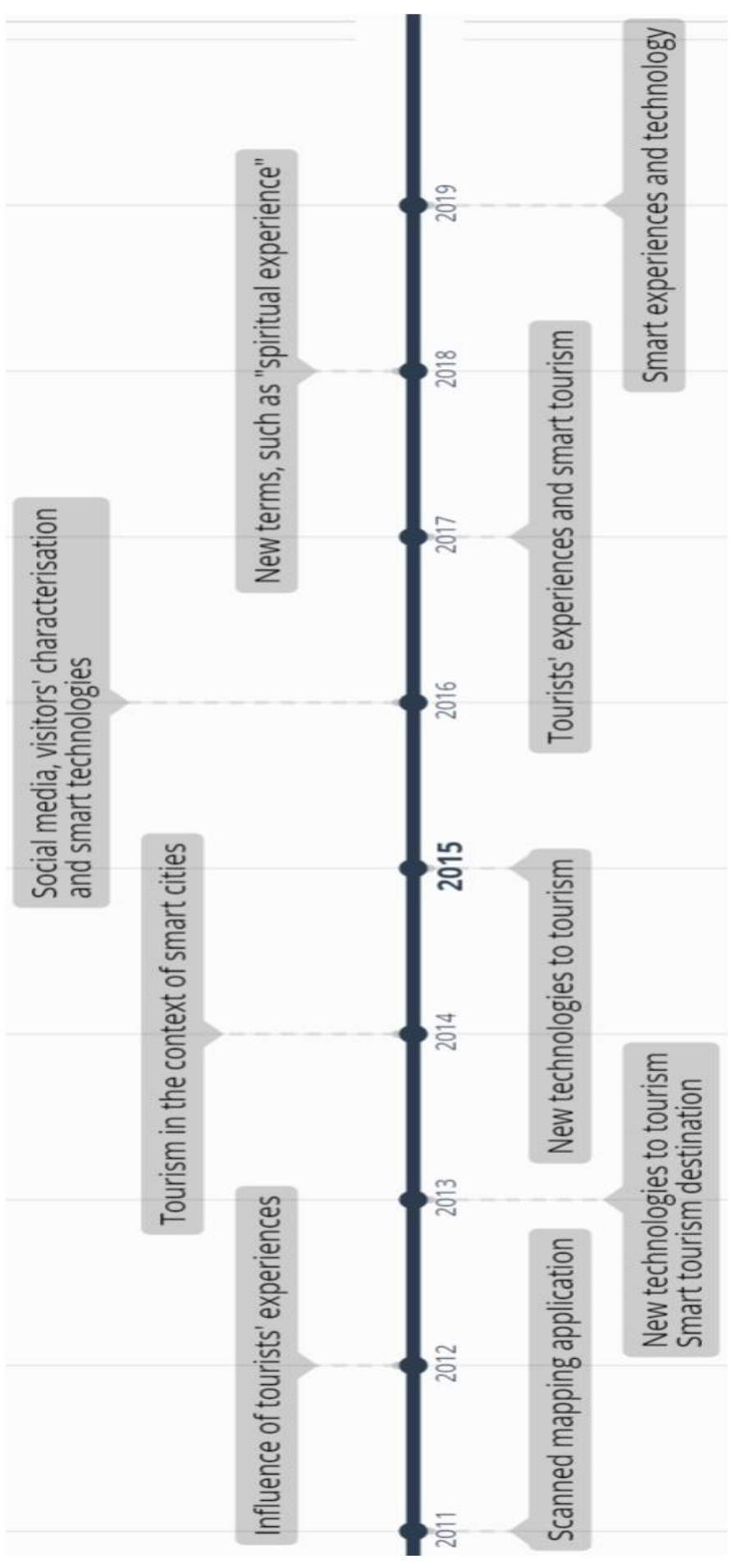


As seen in Figure 10, 2017 was a fertile year for smart tourism studies, and was characterised by key themes like "e-tourism”, "Smart Tourism Experiences”, "gamification”, "social perception”, "big data”, "mobile technology", "sustainability”, "sensorial experiences", "marketing”, "sex tourism”, "gastronomic heritage" and "commoditisation". This was the year in which the word "experience" finally made it to the list of key themes, although always associated with the use of technologies. Other noteworthy entrances to the list of key themes are "regional development", "city planning" and "sex tourism”, which had not been studied before in the context of smart tourism. In 2018, the focus of most published papers remained on technologies, although new themes emerged, including "sustainable tourism", "tourism services", "behaviour intentions", "smart points" and "interaction”. In addition, "geographical influence" was addressed by studies in this area for the first time. Finally, in 2019, studies on smart technologies remained dominant, along with those on gamification and digital platforms. Nevertheless, new topics also emerged, the most relevant ones being "real-time services", "nowness" and "smart events".

Due to its relevance to the concept of SET, the concept of "nowness" must be addressed here. Nowness is originally understood as the quality or state of existing and occurring in real time. In the context of tourism, nowness relates to understanding the current immediate needs of tourists and meeting them in an automated way through the mediation of integrated smart technologies and devices, providing a real-time smart experience. Figure 11 demonstrates the key themes timeline from 2011 to 2019.

\section{Research approach and suggestions}

Regarding the methods employed, most studies (19) adopt surveys as data collection instruments. The second most popular approach is case study (18), namely single case studies, as only one paper adopted a multiple case study. Finally, some studies use specific methods for the subject, namely game/software/app tests or analyses (4). The remaining studies consist of literature reviews (9) or qualitative comparative studies. Regarding the addressed applications to tourism, in the analysed period, the most prominent were scanned mapping (2011), experiences mediated by smartphones (2012), systems' integration with Google Maps and tourism competitiveness (2013), artificial intelligence (2014), and social media and smart specialisation (2015). In the final years of the analysed period, smart tourism (2016), food experiences (2017), tourism paradigm (2018), smart solutions (2018) and smart events (2019) received the most attention. Within the remaining contributions, gamification is the most relevant.

In terms of suggestions for future studies, the most popular topics were scanned mapping (2011), tourism businesses (2012), advanced automations in tourism (2013) and expanding territory (2014). In 2015, research on content generation, software utilisation, human patterns and mobile technology were suggested the most. In 2016, studies suggested future research on technology implementation and its impacts, as well as on the Internet of things (IoT) and tourism infrastructure. In the following year (2017), studies on technology are once again the most suggested. Moreover, one study calls for future research on commercial experience. In 2018, technology is once again the most suggested subject. However, some studies also call for investigations on smart experiences and spiritual experiences. Finally, in the first quarter of 2019, besides more suggestions for research on the use of technology, studies on smart events and smart services are advised. It should be observed that most studies use complex concepts without minutely addressing them. These include expanding territory, content generation, human patterns, and commercial experience. This scenario shows that: 1) there is no universal consensus on SET; and 2) SET can be a diffuse concept, particularly concerning the meaning of "smart". 


\section{SET concept analysis}

The next stage of the analysis consisted of attempting to grasp the meaning and evolution of the SET concept. To this end, the words "Experience" + "Tourism experience" + "Tourist experiences" were searched in all 84 papers. Results show that both terms (experience and tourism experiences) are only used simultaneously on abstracts and keywords in 10 papers. However, an emerging new concept, "positive emotions and commitment", was found in paper no. 40. The words "tourist experience" appeared in paper no. 50, which focused on travellers' shared experiences, and paper no. 67, which concentrated on the sharing of tourists' perceptions. Moreover, spiritual experience is addressed in paper no. 54, while paper no. 83 focused on smartphones and mobile communication, particularly on their potential to significantly influence tourists' experiences. Finally, some interesting concepts are presented in paper no. 51, such as "traveller's readiness" and "hedonic technology". This paper focused on the perspective of traveller's readiness and technology acceptance model with a hedonic view.

\section{Discussion}

The addressed results allowed the authors to tackle the pre-established research questions. In this context, this section presents a discussion of such results considering the existing literature on SET and organised as to clarify each research question.

\section{How has the study of SET evolved?}

As evidenced by the results of the evaluative bibliometric analysis, SET emerged as a research topic in 2011 and has grown in popularity since then. In nine years, 84 papers were published on Scopus, and publication numbers increase every year. This indicates that the topic is of current and increasing interest, as it is associated with current issues and phenomena that are relevant for tourism stakeholders. Therefore, the topic presents good opportunities for researchers. This is further evidenced by the journals' productivity results, which show that SET is not of particular interest to just one or a limited set of research outlets. The productivity is indeed quite balanced since only one paper (Sustainability) clearly stands out from the rest.

The fact that Sustainability - a journal clearly focused on contributions to sustainable development has over twice as many publications on SET than the one in the second place (and over three times as many publications than any other journal up to the fourth position) also indicates another trend in SETrelated studies: a special attention to using smart technologies to increase companies' and destinations' sustainability performance. Within the tourism industry, smart technologies are mainly seen as tools to offer enhanced experiences to tourists, and, ultimately, competitive advantages to companies and destinations. However, as stated by Buhalis and Amaranggana (2015), smart experiences must also allow sustainable practices, which, from a broader point of view, are essential for companies' and destinations' long-term success. In this context, the present study's results corroborate Buhalis and Amaranggana's (2015) definition and show that it has been reflected in SET-related research. This contribution is further corroborated by the results on subject categories, as most papers fall under "Geography, Planning and Development", which has over three times as much papers as the one in the second place, "Business and International Management".

Finally, the results of the key theme analysis also present some interesting insights. In general, the analysis reveals that there is a relatively consistent focus on the use of digital technologies by tourism practitioners. However, as new specific topics emerge, there is a slow shift towards tourists' experiences per se. In this vein, technology is slowly moving from the main aspect - almost as an end in itself - to a tool that, if used smartly, that is, in a way that allows for leveraging knowledge and contextual information, can facilitate more meaningful and engaging experiences. In parallel, in line with the trend 
addressed above, technology is also increasingly seen as a tool to combine smarter experiences with an overall more sustainable industry.

What are the main subjects that have been studied within SET?

The trend mentioned in the previous section provides an initial idea about the main subjects addressed in SET-related research. In terms of specific topics addressed, as revealed by the key theme analysis, the early years of SET-related research (2011 to 2013) were dominated by research on digital mapping applications and smartphone applications in general. During these years, the few published studies focused on the functionalities and potential uses of these applications per se.

In the following years (2014 to 2016), smartphone apps remained popular. However, as the number of studies increased and the state of the art evolved, scholars started analysing more specific aspects of such tools, mainly their relationship with tourists' perceptions and experiences within destinations, and the innovation opportunities they reveal to practitioners - business and destination managers. Moreover, more specific technological tools (i.e. augmented reality and smart glasses) and applications (i.e. self-guided tours and heritage interpretation) have been addressed.

In recent years (2017 to early 2019), the trend of diversification of technological tools and applications, as well as that of addressing the perspective of tourists, have continued. New technological tools analysed included gamification techniques, big data harnessing and digital platforms. Regarding applications, providing smart experiences gained significant momentum. The contexts through which these experiences are provided include the provision of real-time services through e-tourism, more engaging interactions with destinations through gamified experiences, and enhanced tourist information through smart devices. Moreover, opportunities for the hospitality industry and for destination marketing have also been highlighted.

\section{How have these topics been approached?}

Regarding how these topics are approached, case studies are by far the most popular technique. This is not surprising in the context of a particularly novel topic, in which theories are still being created. Case studies are quite useful to analyse new phenomena, perceive patterns and inform new theories (Adams, Hafiz, Raeside, \& White, 2007), which might be further tested through more structured (and potentially more positivistic) research approaches.

Although they are used in a far less expressive proportion of the analysed studies, specific methods based on new information technologies deserve special attention. These methodological tools are very specific to the context of smart experiences, or to the application of smart technology to tourism in general. In this context, they open a new world of possibilities for tourism research as they gather data directly from sources like digital platforms or devices, and in some instances, even biometric sensors. This allows researchers to overcome limitations that are inherent to social science studies, such as overreliance on surveys or interviews, and the consequent potential research biases. When information about tourists' behaviour or preferences is coming directly from hard data, there are no filters involved. Therefore, the information will be more reliable than even the supposedly most sincere survey response.

\section{Conclusions}

The present study aimed to examine the evolution of SET as a research topic by mapping the scientific production on it. This was achieved through an integrative bibliometric approach including the analysis of evaluative measures (productivity and impact metrics) and relational techniques (word frequency analysis and key theme analysis), whereas the latter was further explored via mind maps. 
The evaluative bibliometric analysis revealed an upwards trend in publications on SET, as well as an expansion of SET into other research areas. This indicates that it is a topic of current and increasing interest, which is in line with relevant issues and phenomena for the industry, and therefore offers good opportunities for researchers. Findings from the key theme analysis show that, although the reviewed papers, in theory, deal with the concept of smart experiences, they more often address aspects more closely related to the application of specific technologies, such as augmented reality, smart glasses, mobile apps, and digital recommendations. However, a more detailed analysis also reveals that such focus is gradually shifting. In the early years, the focus was on the application of technology per se. As the topic matures, not only more technological tools and applications are addressed, but they are also increasingly seen as tools to leverage knowledge and contextual information in order to provide meaningful experiences to tourists. Accordingly, tourists' perspectives regarding the use of these technologies and the outcomes for their own experience are increasingly considered by scholars.

In parallel to this increasing consideration of tourists' perspectives and experiences, another important trend in SET-related research deserves special attention: a focus on sustainability. The preferred journal (Sustainability) and subject area ("Geography, Planning and Development") suggest that using technology to combine more meaningful experiences with a better sustainability performance of tourism businesses and destinations is amongst the main topics addressed by SET research. This is in line with definitions of smart experiences from tourism scholars such as Buhalis and Amaranggana (2015), according to whom smart experiences must not only add value to tourists' experiences but, in doing so, also allow for sustainable practices.

The present study contributes to the academic knowledge on SET, as it summarises and systematises the theoretical contributions in the area. More specifically, it provides a general idea of what most authors understand by SET, which, as previously addressed, has been shifting over time. Moreover, as the literature on SET had not been systematically and critically analysed and mapped in previous studies, this is an original outcome that adds to the existing literature concerning bibliometric analysis within the tourism filed. In terms of practical implications, findings point to ways in which destination and tourism product managers can enhance their consumers' experiences using information technology, such as by optimising the smart tourism ecosystem. Naturally, such implications do not stem from any first-hand data provided by the study. They are simply inferred from the joint systematic analysis of previous studies. Moreover, the work provides a methodological contribution for literature reviews in general, as it employs an innovative method that combines bibliometric analysis and content analysis aided by mind maps. Such a method can be used to map the academic literature on other specific areas or phenomena.

Despite the innovativeness and potential of the adopted method, it also implies some limitations. First, its optimal execution requires that all analysed works clearly indicate the information referred to in each analysed category. That is very unlikely to be the case in any substantial body of literature, and unsurprisingly, was not the case within the present analysis. To overcome this, the authors needed to extensively read and interpret all the obtained papers in order to classify them according to the qualitative variables of analysis. Naturally, this severely limits the method's applications to a larger literature database. Another limitation stems from the state in which SET research currently is. The analysis aimed to understand the nature and evolution of SET as a research topic. However, most authors do not clearly define it, which also limited the extent to which this goal was achieved.

Considering the addressed limitations, searching for additional keywords could lead to a more comprehensive review and understanding of SET as a research topic, which, in turn, would require 
innovative methods and approaches of bibliometric and content analysis. In this regard, network analysis could be conducted in future research. Future studies could also use concept maps to provide a clear understanding of the topic's progress. In addition, it would be advisable to complement the studies analysed here with exploratory qualitative studies, for instance, through semi-structured interviews with tourists, aiming to deepen the understanding of the relationship between technology and human experience. Moreover, future studies could critically analyse some concepts that were presented in many of the reviewed articles, as defining and addressing them was beyond the scope of the present investigation. These concepts include "tourist emotions and commitment", "spiritual experience", "tourists' perceived experience", and "hedonic view of the smart experience".

Finally, as a suggestion for SET research in general, the present investigation also points to the use of digital devices as data collection instruments. The few studies that employ this type of data collection prove its potential to collect a whole new dimension of data that was previously inaccessible. They also reveal the potential of collecting data about tourists' behaviour and preferences in a much more reliable manner. Despite this potential, most studies on SET are still based on case studies. Therefore, further studies should collect data through digital devices in order to harness this potential and further contribute to the comprehension of this phenomenon.

Funding: "This research is funded by national funds through FCT - Foundation for Science and Technology, I.P., within the scope of the UIDB / o4470/2020 project". 
Appendix 1. Sample on SET data

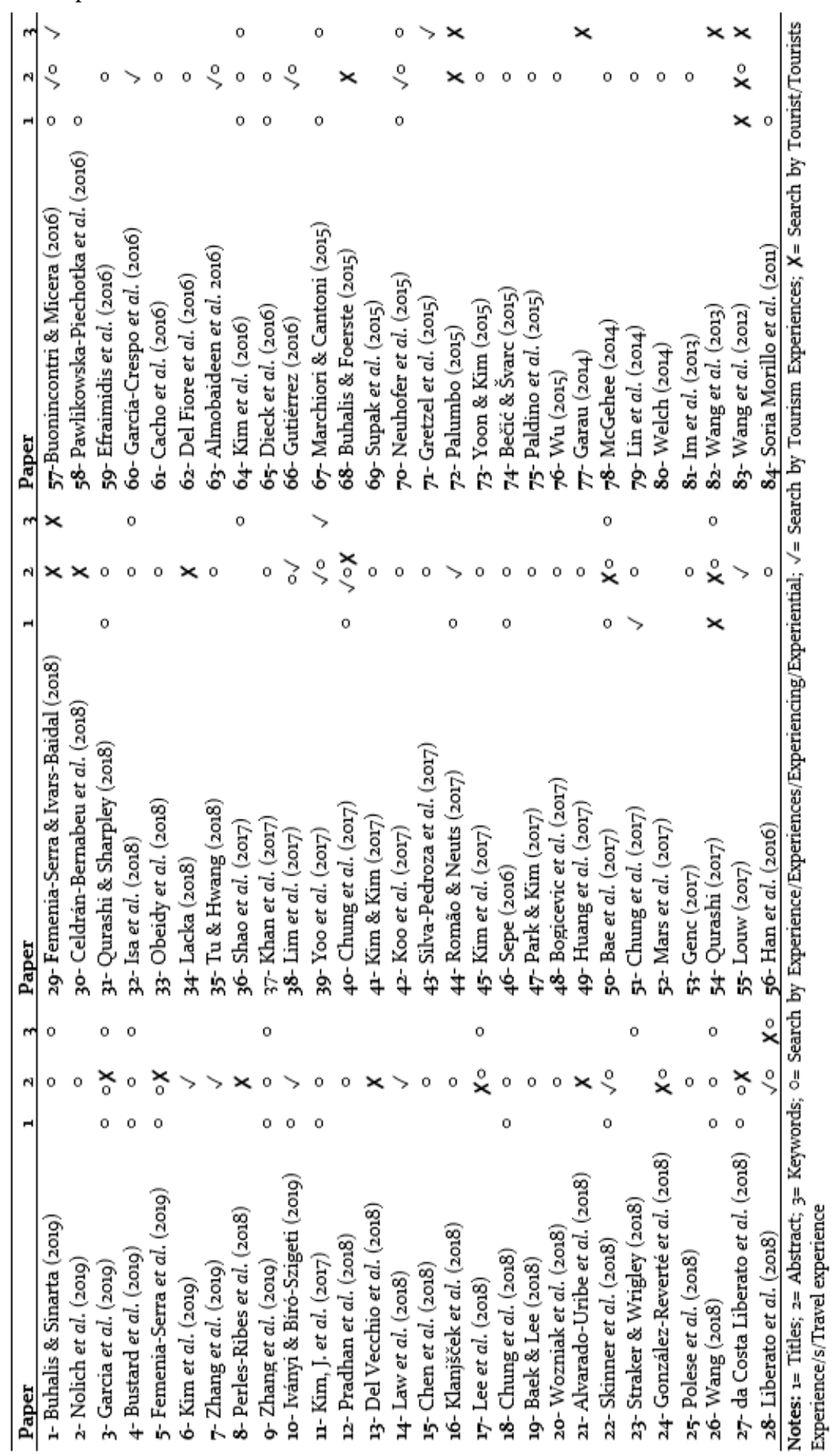




\section{References}

Adams, J., Hafiz, T. A. K., Raeside, R., \& White, D. (2007). Research Methods for Graduate Business and Social Science Students. New Dehli: Sage.

Almeida, G. G. F. (2018). Marca territorial como produto cultural no âmbito do Desenvolvimento Regional: o caso de Porto Alegre, RS, Brasil. Thesis (PhD in Regional Development) - University de Santa Cruz do Sul, Santa Cruz do Sul-RS, Brasil. Available: http://hdl.handle.net/11624/2246.

Benckendorff, P., \& Zehrer, A. (2013). A network analysis of tourism research. Annals of Tourism Research, 43, 121-149.

Bosman, J., Mourik, I. V., Rasch, M., Sieverts, E., \& Verhoeff, H. (2006). Scopus reviewed and compared: The coverage and functionality of the citation database Scopus, including comparisons with Web of Science and Google Scholar. Utrecht University Library.

Buhalis, D. (2003). eTourism: Information technology for strategic tourism management. Pearson education.

Buhalis D., Amaranggana A. (2015) Smart Tourism Destinations Enhancing Tourism Experience through Personalisation of Services. In: Tussyadiah I., Inversini A. (eds) Information and Communication Technologies in Tourism 2015. Springer, Cham. https://doi.org/10.1007/978-3-319-14343-9_28

Buonincontri, P., \& Marasco, A. (2017). Enhancing cultural heritage experiences with smart technologies: An integrated experiential framework. European Journal of Tourism Research, 17, 83101.

Buonincontri, P., \& Micera, R. (2016). The experience co-creation in smart tourism destinations: a multiple case analysis of European destinations. Information Technology \& Tourism, 16(3), 285-315.

Buzan, T. (2013). Mind Map Handbook: The ultimate thinking tool. Thomsons.

Cardoso, L., Dias, F., de Araujo, A., \& Marques, I. (2019). A destination imagery processing model: Structural differences between dream and favourite destinations. Annals of Tourism Research, 74, 81-94.

Cheng, M., Edwards, D., Darcy, S., \& Redfern, K. (2018). A Tri-Method Approach to a Review of Adventure Tourism Literature: Bibliometric Analysis, Content Analysis, and a Quantitative Systematic Literature Review. Journal of Hospitality and Tourism Research, 42(6), 997-1020.

Del Río-Rama, M., Maldonado-Erazo, C., \& Âlvarez-García, J. (2018) State of the art of research in the sector of thermalism, thalassotherapy and spa: A bibliometric analysis. European Journal of Tourism Research, 19, 56-70.

Del Río-Rama, M., Maldonado-Erazo, C., Durán-Sánchez, A., \& Álvarez-García, J. (2019) Mountain tourism research. A review. European Journal of Tourism Research, 22, 130-150.

Fahimnia, B., Sarkis, J., \& Davarzani, H. (2015). Green supply chain management: A review and bibliometric analysis. International Journal of Production Economics, 162, 101-114.

Femenia-Serra, F., \& Neuhofer, B. (2018). Smart tourism experiences: conceptualisation, key dimensions and research agenda. Journal of Regional Research, 42, 129-150.

Femenia-Serra, F., Perles-Ribes, J. F., \& Ivars-Baidal, J. A. (2019). Smart destinations and tech-savvy millennial tourists: hype versus reality. Tourism Review, 74(1), 63-81.

Gretzel, U. (2018). From smart destinations to smart tourism regions. Investigaciones Regionales: Journal of Regional Research, 42, 171-184.

Gretzel, U., Ham, J., \& Koo, C. (2018). Creating the city destination of the future: The case of smart Seoul. Managing Asian Destinations, 199-214.

Gretzel, U., Sigala, M., Xiang, Z., \& Koo, C. (2015). Smart tourism: foundations and developments. Electronic Markets, 25(3), 179-188.

Gretzel, U., Werthner, H., Koo, C., \& Lamsfus, C. (2015). Conceptual foundations for understanding smart tourism ecosystems. Computers in Human Behavior, 50, 558-563. 
Gretzel, U., Zhong, L., \& Koo, C. (2016). Application of smart tourism to cities. International Journal of Tourism Cities, 2 (2).

Güzeller, C. O., \& ÇeliKer, N. (2018). Bibliometric analysis of tourism research for the period 2007-2016. Advances in Hospitality and Tourism Research, 6(1), 1-22.

Hwang, J., Park, H. Y., \& Hunter, W. C. (2015). Constructivism in smart tourism research: Seoul destination image. Asia Pacific Journal of Information Systems, 25(1), 163-178.

Johnson, A.-G., \& Samakovlis, I. (2019). A bibliometric analysis of knowledge development in smart tourism research. Journal of Hospitality and Tourism Technology, 10(4), 600-623.

Koo, C., Yoo, K. H., Lee, J. N., \& Zanker, M. (2016). Special section on generative smart tourism systems and management: Man-machine interaction. International Journal of Information Management, 36(6), 1301-1305.

Koseoglu, M. A., Rahimi, R., Okumus, F., \& Liu, J. (2016). Bibliometric studies in tourism. Annals of Tourism Research, 61, 180-198.

Leong, L.-Y., Hew, T.-S., Tan, G. W.-H., Ooi, K.-B., \& Lee, V.-H. (2020). Tourism research progress - a bibliometric analysis of tourism review publications. Tourism Review, (forthcoming).

Meneguel, C. R. de A., Rubio, S. P., \& Mundet, L. (2019). Análisis Bibliométrico de la Investigación Turística sobre la Ciudad de Girona. Revista Rosa Dos Ventos - Turismo e Hospitalidade, 11(3), 598614.

Molinos, D. N., Mesquita, D. G., \& Hoff, D. N. (2016). ZipfTool: Uma ferramenta bibliométrica para auxílio na pesquisa teórica. Revista de Informática Teórica e Aplicada, 23(1), 293-317.

Niñerola, A., Sánchez-Rebull, M. V., \& Hernández-Lara, A. B. (2019). Tourism research on sustainability: A bibliometric analysis. Sustainability, 11(5), 1-17.

Padrón-Ávila, H., \& Hernández-Martín, R. (2020). How can researchers track tourists? A bibliometric content analysis of tourist tracking techniques. European Journal of Tourism Research, 26, 2601.

Pine, B. J., \& Gilmore, J. H. (1998). Welcome to the experience economy. Harvard business review, 76, 97-105.

Porter, M. E., \& Heppelmann, J. E. (2014). How smart, connected products are transforming competition. Harvard business review, 92(11), 64-88.

Sánchez, A., Del Río-Rama, M., \& García, J. (2017). Bibliometric analysis of publications on wine tourism in the databases Scopus and WoS. European Research on Management and Business Economics, 23(1), 8-15.

Schreier, M. (2012). Qualitative content analysis in practice. Sage Publications.

Sigala, M. (2015). The application and impact of gamification funware on trip planning and experiences: The case of TripAdvisor's funware. Electronic Markets, 25(3), 189-209.

Tregua, M., D’Auria, A., \& Costin, H. (2020). \#10yearschallenge: how co-creation permeated tourism research. A bibliometric analysis. European Journal of Tourism Research, 24, 2409.

Walle, A. H. (1996). Tourism and the Internet: opportunities for direct marketing. Journal of travel research, 35(1), 72-77.

Wheeldon, J. (2011). Is a Picture Worth a Thousand Words? Using Mind Maps to Facilitate Participant Recall in Qualitative Research. The Qualitative Report, 16(2), 509-522.

Xiang, Z., \& Gretzel, U. (2010). Role of social media in online travel information search. Tourism management, 31(2), 179-188.

Ye, Q., Song, H., \& Li, T. (2012). Cross-institutional collaboration networks in tourism and hospitality research. Tourism Management Perspectives, 2-3, 55-64.

Received: 13/07/2020

Accepted: 14/10/2020

Coordinating editor: Stanislav Ivanov 